\title{
Upregulation of NKG2D ligands and enhanced natural killer cell cytotoxicity by hydralazine and valproate
}

\author{
A. CHÁVEZ-BLANCO ${ }^{1,2}$, E. DE LA CRUZ-HERNÁNDEZ ${ }^{1}$, G.I. DOMÍNGUEZ ${ }^{1}$, O. RODRÍGUEZ-CORTEZ ${ }^{2}$, \\ B. ALATORRE ${ }^{1}$, E. PÉREZ-CÁRDENAS ${ }^{1}$, R. CHACÓN-SALINAS ${ }^{2}$, C. TREJO-BECERRIL ${ }^{1}$, \\ L. TAJA-CHAYEB ${ }^{1}$, J.E. TRUJILLO ${ }^{1}$, A. CONTRERAS-PAREDES ${ }^{1}$ and A. DUEÑAS-GONZÁLEZ ${ }^{3}$ \\ ${ }^{1}$ División de Investigación Básica, Instituto Nacional de Cancerología; ${ }^{2}$ Departamento de Inmunología, Sección \\ de Estudios de Posgrado e Investigación, Escuela Nacional de Ciencias Biológicas, IPN; ${ }^{3}$ Unidad de Investigacion \\ Biomédica en Cancer Instituto de Investigaciones Biomédicas, UNAM/Instituto Nacional de Cancerología, México
}

Received May 16, 2011; Accepted June 30, 2011

DOI: 10.3892/ijo.2011.1144

\begin{abstract}
Natural killer cells play a role in the immune antitumor response by recognizing and eliminating tumor cells through the engagement of NKG2D receptors with their ligands on target cells. This work aimed to investigate whether epigenetic drugs are able to increase MICA and MICB expression as well as NK cell cytotoxicity. Prostate, colon, breast and cervical cancer cell lines were analyzed for the expression of MICA and MICB at the mRNA and protein levels by RT-PCR, Western blot, flow cytometry and ELISA. The activating mark H3K4m2 at the MICA and MICB promoters was investigated by ChIP assays. Cytotoxicity of NK cells against the target epithelial cancer cells was investigated with the CD107 cytotoxicity assay. The results show that hydralazine and valproic acid not only increase the expression of MICA and MICB ligands of target cells, but also reduce their shedding to the supernatant. This upregulation occurs at the transcriptional level as revealed by increase of the $\mathrm{H} 3 \mathrm{~K} 4$ activating mark at the promoter of MICA and MICB genes. These effects are paralleled by increased cytotoxicity of NK cells, which was attenuated at different degrees by using blocking antibodies against the NKG2D receptor and ligands. In conclusion, our results demonstrate the ability of hydralazine and valproate to increase the NK activity against epithelial cancer cell lines and suggest that these drugs could reduce the levels of soluble MICA and MICB helping in avoiding tumor-induced suppression of NK cytotoxicity against the tumor.
\end{abstract}

\section{Introduction}

DNA hypermethylation and histone deacetylation are critical for determining a closed chromatin structure responsible for or

Correspondence to: Dr Alfonso Dueñas González, Primer Piso, edificio de Investigación. San Fernando 22, Mexico City, Tlalpan 14080, Mexico

E-mail: alfonso_duenasg@yahoo.com

Key words: NKG2D ligands, NK cells, hydralazine, valproate related with aberrant gene transcription in malignancies (1). DNA methylation and histone deacetylase inhibitors exert antitumor effects by inhibiting cell proliferation, metastases, angiogenesis, and by inducing cell differentiation and/or apoptosis, as well as by increasing chemotherapy cytotoxicity (2-6). Nevertheless, chromatin remodeling agents also show promise for immune therapy of cancer. It is known that several immune escape mechanisms allow tumors to go undetected; for instances, epigenetic downregulation of genes involved in antigen processing and presentation has been described which is reversed by DNA methylation and histone deacetylation inhibitors allowing tumor recognition by the immune system (7-9).

DNA methylation and other epigenetic mechanisms are also important for the establishment and maintenance of diverse repertories of clonally restricted KIR and Ly49 receptors in Natural killer (NK) (10) cells which are components of the innate immunity that substantially contributes to the elimination of virus-infected cells $(11,12)$ as well as to antitumor immune responses (13). Epigenetic control of their expression produces specific combinations of multiple receptors on each NK cell, and a population-wide repertoire that allows correct responses to changes in the MHC ligand environment (10).

NKG2D is a type II transmembrane anchored C-type lectinlike molecule expressed as a disulfide-linked homodimer on the surface of NK cells and various $\mathrm{T}$ cell subsets including $\mathrm{CD}^{+}$ $\alpha / \beta^{+} \mathrm{T}$ cells, $\gamma / \delta^{+} \mathrm{T}$ cells and NKT cells. In humans, NKG2D binds to MHC class I-related chain A (MICA), MHC class I related chain $\mathrm{B}$ (MICB), and a structurally distinct family of UL16-binding protein (ULBP) proteins $(14,15)$. The role of NK cells in immunosurveillance against tumors has been widely demonstrated in syngeneic murine models where their depleting results in increased aggressive growth and metastatic ability of tumors $(16,17)$. Likewise, NK cells deficiency or some of their receptors or effector molecules causes a high incidence of tumors in spontaneous or induced tumor models (18). NKG2D ligands are not expressed in normal cells, but are upregulated in cancer cells, which elicit a potent antitumor immune response in vitro and in vivo, when the tumor is not rejected or eliminated; the immune system sculpts the phenotype in tumor cells, and eliminate the cells more immunogenic favoring the growth of less immunogenic cells (19). Here we demonstrate that the 
DNA demethylating inhibitor hydralazine in combination with valproic acid are able to enhance the natural killer cell-mediated cytotoxicity against epithelial cancer cells via increased expression of NKG2D ligands.

\section{Materials and methods}

Human prostate cancer cell line DU145, colon cancer cell line SW480, breast cancer cell line T47D and cervical cancer cell line CaSki, obtained from the ATCC, were cultured at $37^{\circ} \mathrm{C}$ with $5 \% \mathrm{CO}_{2}$ in DMEM-F12 medium supplemented with $10 \%$ heatinactivated fetal bovine serum. Hydralazine $(\mathrm{H})$ and magnesium valproate (V) were obtained from Sigma and added at $10 \mu \mathrm{M}$ and $1 \mathrm{mM}$ for 5 days. Medium with freshly prepared drugs was replaced daily.

RNA extraction and real-time PCR. RNA was isolated using TRIzol (Invitrogen) according to the manufacturer's instructions. Reverse transcription of $1 \mu \mathrm{g}$ RNA was carried out using GeneAmp RNA PCR Core kit (Applied Biosystems) and stored at $20^{\circ} \mathrm{C}$ until use. NKG2D ligands gene expression was carried out using an iCycler (Bio-Rad) with specific primers for MICA sense 5'-CTGGTGCTTCAGAGTCATTGG-3', antisense 5'-GAAATCCGAGCTGTGTGGCAT-3'; and MICB sense 5'-GACCAAGACACACTATCGCG-3', antisense 5'-CATGTCACGGTGATGTTGCC-3'.

Chromatin immunoprecipitation (ChIP) assay. Cancer cell lines treated with $\mathrm{H}$ and $\mathrm{V}$ as above described, were fixed with $1 \%$ formaldehyde for $10 \mathrm{~min}$ at room temperature and neutralized by addition of glycine at a final concentration of $0.125 \mathrm{M}$ for $5 \mathrm{~min}$. Fixed cells were suspended in $1 \mathrm{ml}$ of lysis buffer (1\% SDS, 10 mM EDTA, 50 mM Tris-HCl, pH 8.0, 0.2 mM PMSF, $5 \mu \mathrm{g} / \mathrm{ml}$ aprotinin, $1 \mu \mathrm{g} / \mathrm{ml}$ leupeptin, and $5 \mu \mathrm{g} / \mathrm{ml}$ sonicated salmon sperm DNA. Following 30 min incubation on ice, samples were sonicated for $10 \times 20 \mathrm{sec}$, with at least $1 \mathrm{~min}$ intervals on ice. Samples were then spun for $10 \mathrm{~min}$ at a maximum speed at $4^{\circ} \mathrm{C}$, and the supernatants were collected. Protein-chromatin complexes were immunoprecipitated overnight with dimethylhistone $\mathrm{H} 3$ (Lys4) antibody (Millipore) and rotated at $4^{\circ} \mathrm{C}$. The chromatin was collected with protein A-agarose/salmon sperm DNA (Millipore). The beads were washed sequentially with $1 \mathrm{ml}$ of each following buffer for $5 \mathrm{~min}$ : IP dilution buffer (0.1\% SDS, $1 \%$ Triton X-100, 1 mM EDTA, 0.5 mM EGTA, $0.1 \%$ Na-deoxycholate, $10 \mathrm{mM}$ Tris-HCl, $\mathrm{pH} 8.0$, and $150 \mathrm{mM}$ $\mathrm{NaCl})$, washing buffer (0.1\% SDS, $1 \%$ Triton $\mathrm{X}-100,1 \mathrm{mM}$ EDTA, 0.1\% Na-deoxycholate, $10 \mathrm{mM}$ Tris-HCl, $\mathrm{pH}$ 8.0, and $500 \mathrm{mM} \mathrm{NaCl})$, and $\mathrm{LiCl}$ buffer ( $0.25 \mathrm{M} \mathrm{LiCl}, 0.5 \% \mathrm{NP} 40,0.5 \%$ Na-deoxycholate, $1 \mathrm{mM}$ EDTA, and $10 \mathrm{mM}$ Tris-HCl, $\mathrm{pH}$ 8.0), followed by washing for 3 times with cold TE buffer (pH 8.0). Precipitates were then extracted by incubating with elution buffer ( $1 \%$ SDS, $\left.0.1 \mathrm{M} \mathrm{NaHCO}_{3}\right)$ at $65^{\circ} \mathrm{C}$ overnight and with $1 / 25$ volume of $5 \mathrm{M} \mathrm{NaCl}$ for $4-6 \mathrm{~h}$ at $65^{\circ} \mathrm{C}$. DNA was purified with phenol/chloroform/isoamyl alcohol for PCR-amplification. The following PCR primers were used for amplifying the human promoter MICA sense 5'-CGACGTCGCCACCCTCTCA-3', antisense 5'-CCAGGTCCCGCCTTCTAAAT-3' and promoter MICB sense 5'-CTACGTCGCCACCTTCTCAGCTG-3', PCR products were separated on a $2 \%$ agarose gel and visualized by ethidium bromide staining.
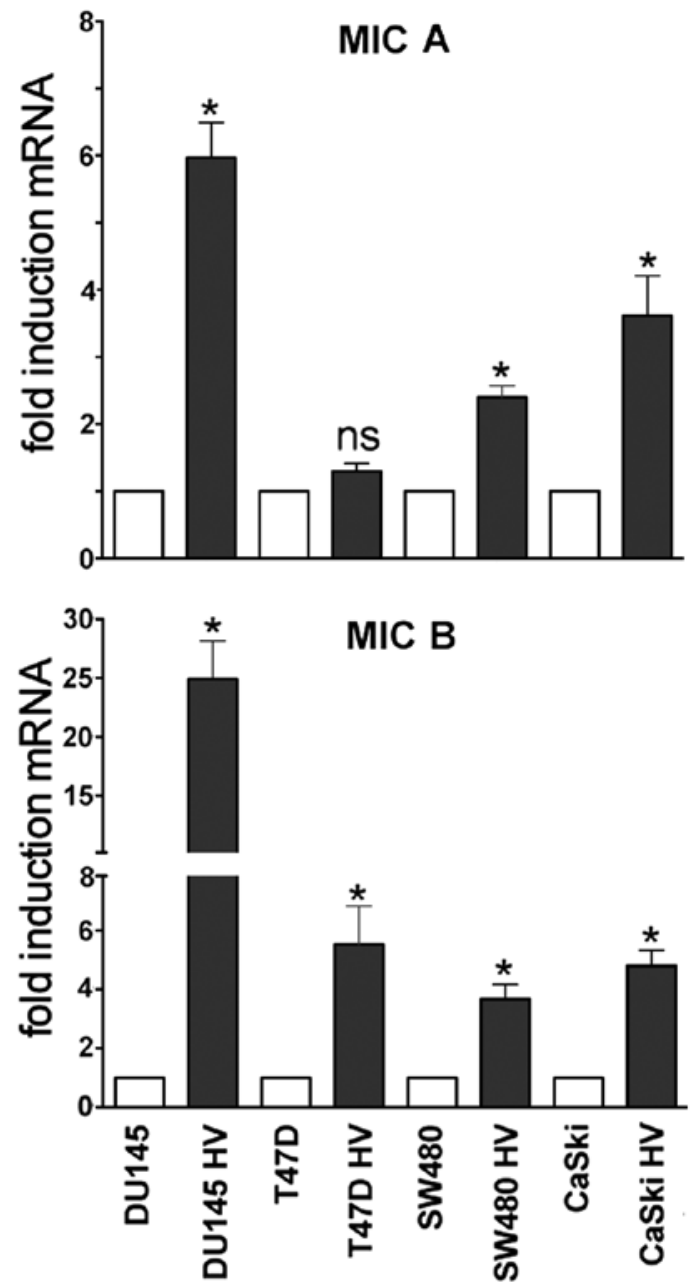

Figure 1. Effect of $\mathrm{HV}$ on the expression of MICA and MICB genes. The gene expression levels relative to GAPDH were determined using real-time PCR. Each column and error bar represents the mean \pm SD of the ratios of the NKG2DL. Results from three independent experiments. ${ }^{*} \mathrm{p}<0.05$, ns $=$ nonsignificant.

Immunofluorescence staining. Fluorescence microscopy was done as previously described (20). In brief, cells were grown on coverslips until $60 \%$ confluence before treatment with HV. After 5 days, cells were fixed with acetone at $4^{\circ} \mathrm{C}$. Coverslips were blocked and subsequently incubated with mouse anti-MICA/B (6D4) (Santa Cruz Biotechnology, Inc.) or isotype control, respectively, followed by incubation with a secondary goat anti mouse AF-594 (Invitrogen) and mounted with ProLong Gold DAPI (Invitrogen), coverslips were examined using a fluorescence microscope.

Flow cytometry. Cell lines were detached from culture dishes using PBS/EDTA, incubated with mouse anti-human MICA/B (6D4), goat anti-human ULBP-1, rabbit anti-human ULBP-2, rabbit anti-human ULBP-3, antibodies purchased from Santa Cruz Biotechnology. FITC-labeled rat anti-mouse IgG, FITClabeled goat anti-rabbit, FITC-labeled donkey anti-goat was purchased from eBioscience (San Diego, CA), finally analyzed on a FACSCalibur (Becton-Dickinson, Mountain View, CA). The data were analyzed with FlowJo 8.7 software (Tree Star, Inc.). 


\section{mAb H3K4 dimethylated}

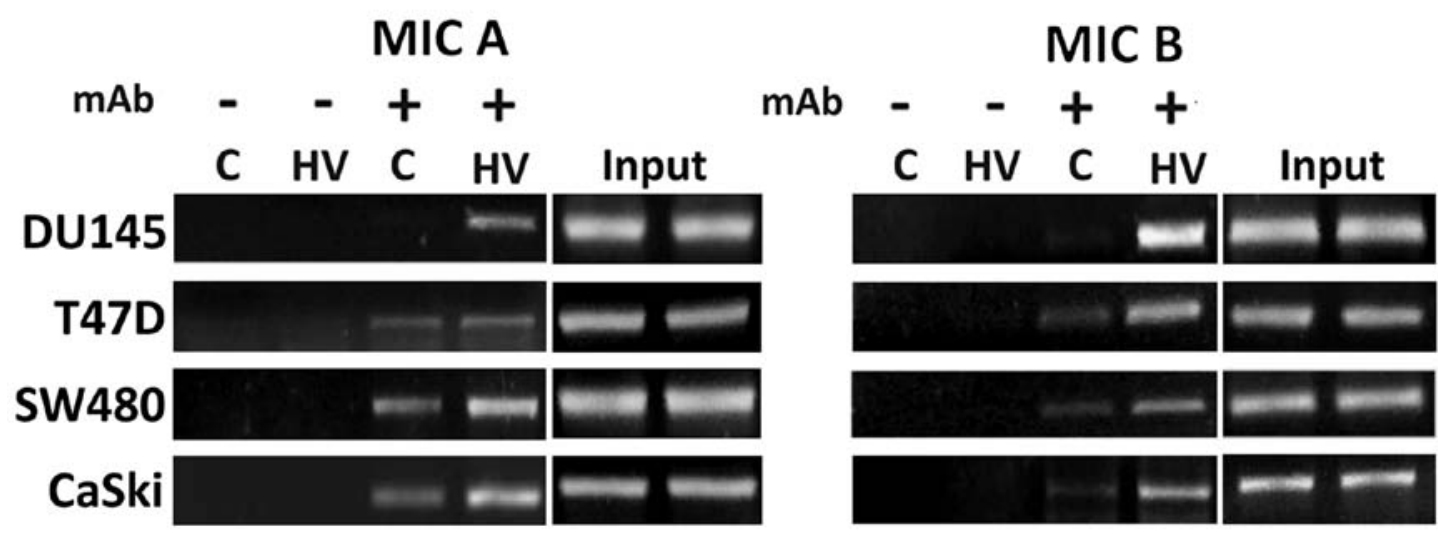

Figure 2. HV increased the expression of the transcriptional activation mark dimethylated H3K4 in MICA and MICB promoters. Cell lines were treated with 10 mM hydralazine and $1 \mathrm{mM}$ valproate for five days as indicated (HV). After formaldehyde crosslinking, soluble chromatin from cell lysates was immunoprecipitated with antibodies anti dimethylated $\mathrm{H} 3 \mathrm{~K} 4$

ELISA assay. The supernatants of cultured cells were harvested after 5 days with HV, the levels of soluble MICA were determined with an ELISA kit (DuoSet, RyD System) according to the manufacturer's protocol.

Isolation of NK cells. Primary NK cells were obtained from peripheral blood lymphocytes and isolated by Ficoll-Hypaque density gradient centrifugation (Amersham Pharmacia Biotech) from heparinized venous blood obtained from normal healthy volunteer donors. NK cells were purified with a NK cell isolation kit (Miltenyi Biotec, Auburn, CA). Non-NK cells were magnetically labeled indirectly, using a mixture of biotin-conjugated antibodies and the NK Cell MicroBead Cocktail. Isolation of highly pure NK cells was achieved by depletion of magnetically labeled cells. The percentage of NK cells after isolation was evaluated using FITC-conjugated anti-CD3 mAbs and PE-conjugated anti-CD56 mAbs (BD PharMingen) in flow cytometry, and routinely exceeded $95 \%$.

CD107 cytotoxicity assay. The CD107 assay with the cancer cell lines was set up as described (21). Briefly, cancer cells DU145, T47D, SW480 and CasKi, were plated at various cell numbers in a 96 -well plate and incubated at $37^{\circ} \mathrm{C}$ and treated by 5 days with $\mathrm{HV}$. On the day of the assay, the culture supernatant was removed from the wells and the effector NK cells were added to the wells at various E: T ratios (100:1, 50:1, 25:1). Control wells contained either only NK cells, only tumor target cells, anti MICA/B in target cells and anti NKG2D (1D11) in the well with NK cells. Ten microliters each of CD107-biotin was added to each well at the same time as addition of the NK cells. The plate was then centrifuged for $3 \mathrm{~min}$ at $1,000 \mathrm{rpm}$ in order to facilitate immediate contact between the NK cells and the target cells at the bottom of the wells. The plate was then incubated at $37^{\circ} \mathrm{C}$ and after the first hour of incubation GolgiStop was added to each of the wells and the plate was returned to the incubator for an additional $4 \mathrm{~h}$. At the end of the incubation period the cells were harvested into separate tubes and washed once with Pharmingen Stain Buffer (PSB, BD Pharmingen, CA) and incu- bated with Streptavidine-APC $30 \mathrm{~min}$, and washed after which they were re-suspended in $1 \mathrm{ml} \mathrm{PSB}$ and stained with anti-human CD56 AF-488 for $30 \mathrm{~min}$. The cells were then washed again and re-suspended in PSB for measuring Median Fluorescence Intensity (MFI) using a FACS Calibur flow cytometer (BectonDickinson).

\section{Results}

The four human epithelial cancer cell lines expressed basal levels of MICA and MICB mRNA. Upon HV treatment for five days at $10 \mu \mathrm{M}$ and $1 \mathrm{mM}$ respectively, a significant increase in MICA expression ranging from almost 3- to 6-fold was observed in all but 747D cells. MICB mRNA expression was also significantly increased in the four cell lines. Of note, the DU145 prostate cancer cell line was the most responsive to treatment (Fig. 1). These results strongly suggest that these two ligands are epigenetically downregulated in epithelial cancer cells. Previous studies have shown the transcriptional activation of these molecules by a histone deacetylase inhibitor depends on the induction of Sp1 transcription factor and binding to the MICA and MICB promoters. To confirm the transcriptional activation by $\mathrm{HV}$ we evaluated by ChIP analysis the activating methylation mark $\mathrm{H} 3 \mathrm{~K} 4 \mathrm{~m} 2$. As expected, an increase in methylation was observed in the four cell lines in both $M I C A$ and $M I C B$ gene promoters except in 747D cells for MICA (Fig. 2) which strongly correlates with the RT-PCR results shown in Fig. 1.

Recognition and NK cell cytotoxicity upon ligand binding against tumor cells require that NKG2D ligands are expressed at the cell surface; hence flow cytometry and immunofluorescence staining assays were performed using an antibody which recognizes both MICA and MICB. The results in Fig. 3A show that indeed $\mathrm{HV}$ not only transcriptionally activates their expression but led to a significant increase in the expression of these molecules in the four epithelial cancer cell lines. This was observed even in 747D cells which showed less transcriptional activation as compared to the other three cell lines. Fig. 3B supports these results as both cytoplasmic and membrane staining were 
A
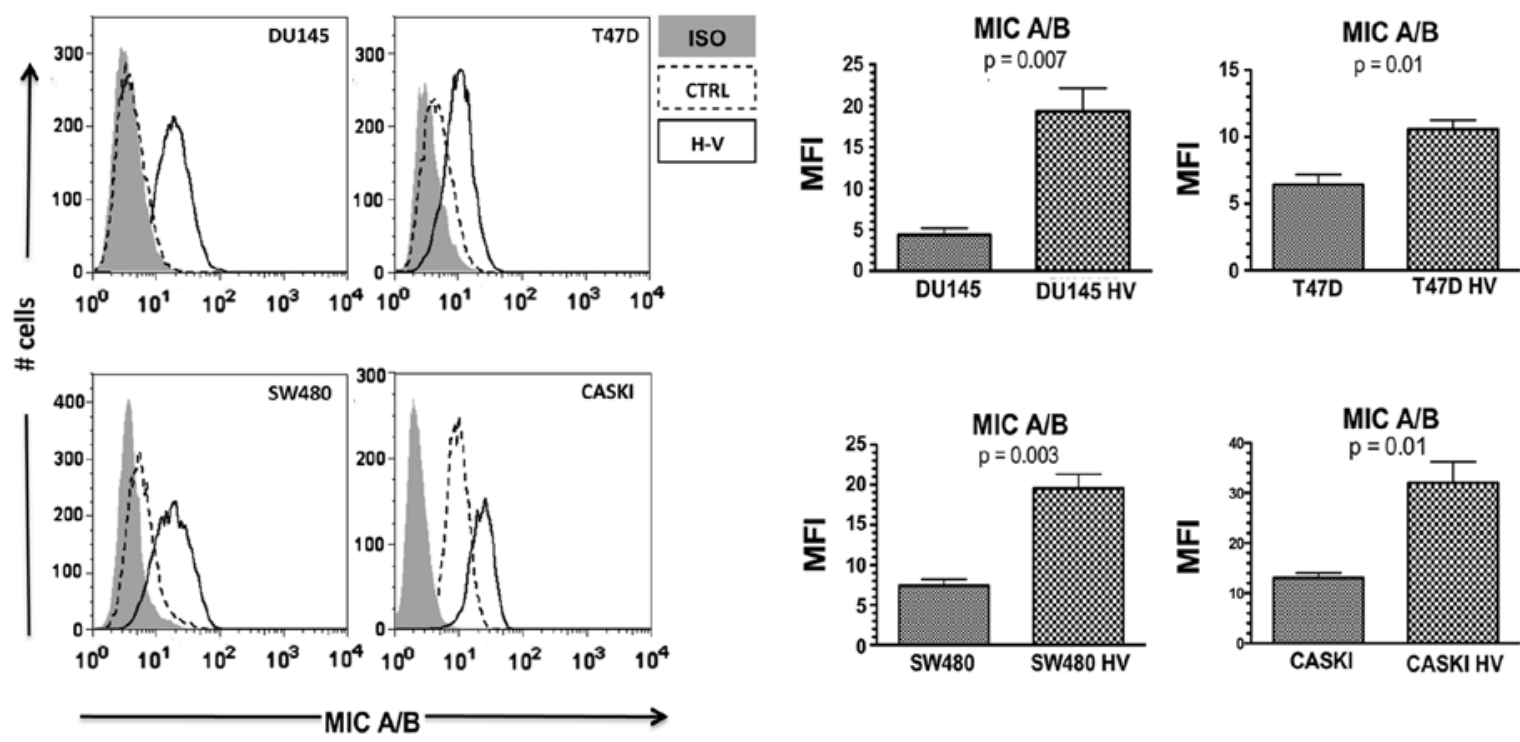

B

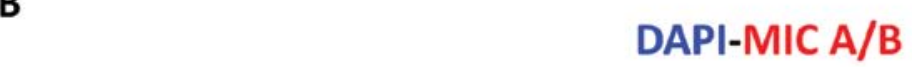

DU145
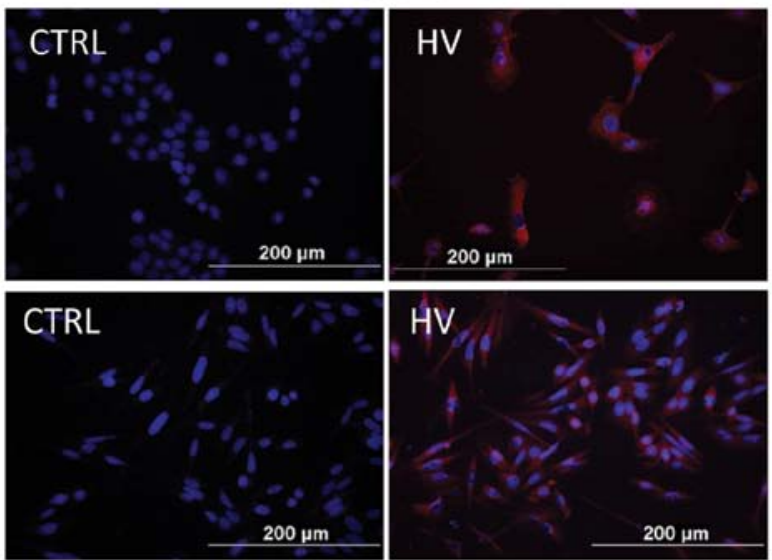

SW480
T47D
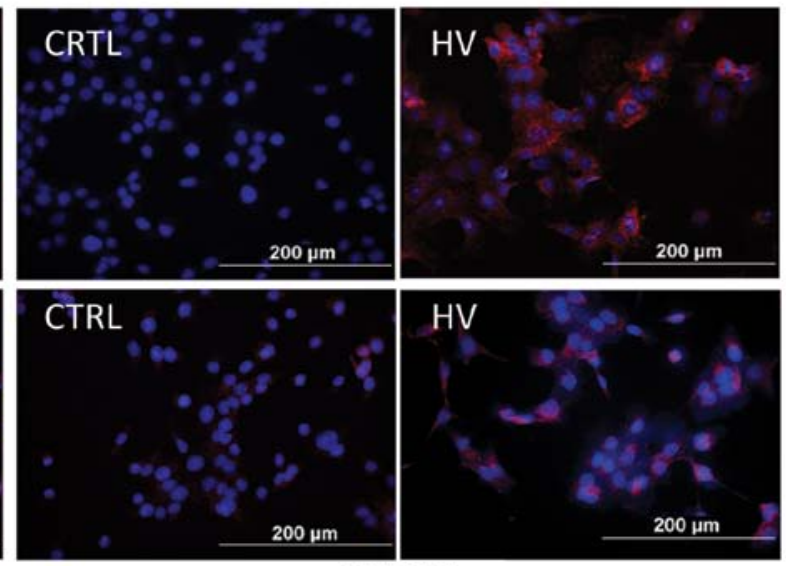

CASKI

Figure 3. MICA and MICB is upregulated by HV in four cell lines. (A) Representative histograms of flow cytometry and MFI, ${ }^{*} \mathrm{p}<0.05,{ }^{* *} \mathrm{p}<0.005$. (B) Staining MICA/B by inmunofluoresense $\mathrm{x} 40$.

observed in the cell lines. To further explore this issue, it was important to investigate the effect of HV treatment in the shedding of these molecules. As shown in Fig. 4, the analysis with an ELISA assay of the supernatant of HV treated cells did not show statistical significance, however, there was a clear reduction in the amount of soluble MICA.

To determine whether increased MICA and MICB in target epithelial cancer cells could increase their susceptibility to NK cells, we measured the cytotoxicity of isolated NK cells from the peripheral blood of healthy individuals. Fig. 5 shows that as expected HV treatment for five days significantly increased the susceptibility of the four cell lines to cytolysis by NK cells. Further, Fig. 5 also shows that this increased lysis depended upon the interaction NKG2D-NKG2D-ligands. The addition of a blocking antibody against the NKG2D receptor in effector cells led to a very strong inhibition of killing. A lesser but still clear inhibition of cytotoxicity was also demonstrated when a blocking antibody against MICA/B was added to the assay. This latter result may suggest that $\mathrm{HV}$ could also induce UL16-binding protein (ULBP) 1, 2 and 3 which are other well-known ligands of the NKG2D receptor whose presence at the surface of target cells triggers NK cell activation and cytotoxicity upon engaging. Fig. 6 clearly shows HV treated cells had a significant increase of all three ULBP ligands at the membrane of the epithelial cancer cells, which may explain the only partial abrogation of killing by NK cells when MICA and MICB were blocked in the cytotoxicity assay.

\section{Discussion}

Hydralazine and valproate are being repositioned as epigenetic drugs for cancer treatment. The results of this study show that 

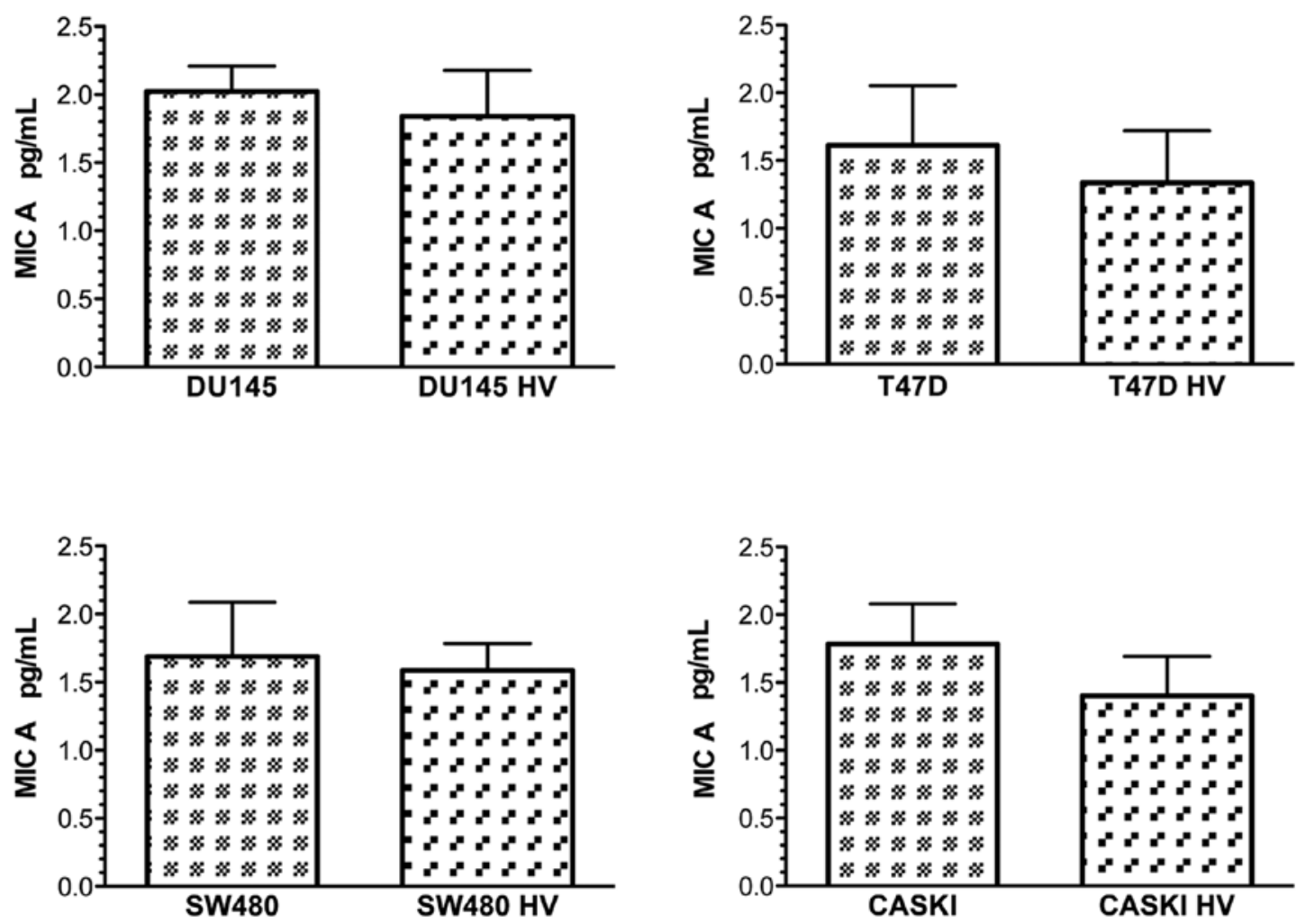

Figure 4. sMICA is not shed by HV in for different human cancer cell lines. sMICA levels in conditioned medium did not changes when the cells were treated with HV. Between different lines treated without and with HV treatment differences were not statistically significant.

in combination, they are able not only to increase the expression of NKG2D ligands at transcriptional level but also to enhance the membrane expression of these ligands in epithelial cancer cells which leads to enhanced NK cell cytotoxicity against these target cells.

Current evidence strongly suggests that activation of the immune system, mediated by engagement of NKG2D receptor with its ligands, plays an important role in immunosurveillance of cancer $(22,23)$, and the expression of NKG2D-L has been described in multiple types of tumors $(24,25)$. Because MICA and MICB are crucial for the activating receptor NKG2D and subsequent killing of tumor cells and it has been shown that these molecules can be downregulated by epigenetic mechanisms as a tumor evolving mechanism to minimize or avoid the response mediated by NKG2D ligands, here we prove that the DNA methylation and HDAC inhibitors hydralazine and valproate, respectively, are able to transcriptionally increase the expression of these ligands in four epithelial cancer cell lines. Though the specific epigenetic process involved in the regulation at the promoter of these genes is yet unknown, hydralazine and valproate most likely led to increased expression via their epigenetic effects as the activating mark H3K4 methylation was induced upon treatment. Another interesting finding was the fact that hydralazine and valproate reduced the shedding of these ligands from the cancer cells being known that soluble NKGD2 ligands have a clear immunosuppressive effect in the host and that their high levels are correlated with a poorer prognosis (26-28). This effect points towards an immunotherapeutic effect of these drugs as tumor cells also increase shedding of NKGD2 ligands from the cell surface as a mechanism of immune evasion (26).
These two effects as well as the increased expression of ULBP 1, 2 and 3 most likely were responsible for the significant increase in the cytotoxicity of NK cells upon the epithelial cancer cells as killing was avoided at different degree by blocking either the receptor or the ligands.

A number of studies have shown that valproate (29-31) and other epigenetic agents including HDAC inhibitors sodium butyrate (32) and trichostatin A (33), as well as the DNA methylation inhibitor 5-aza-2'-deoxycytidine (34) and arsenic trioxide (35) which also inhibits DNA methyltransferase (36) are also able to increase NKGD2 ligands and NK cells cytotoxicity in a variety of hematological and non-hematological malignant models. Thus, our data are in line with previous studies which support the role of epigenetic agents for increasing NK activity against tumor cells. A previous study performed in the AML cell line HL60 and in primary AML blasts, showed an increased expression of ULBP1 by several agents. The highest expression was combining Vitamin D3,5-aza-2'-deoxycytidine, trichostatin A, granulocyte colony-stimulating factor and $\gamma$ interferon (30) nevertheless, the specific contribution for increased expression of either DNA methylation or HDAC inhibitors remains to be demonstrated. In a previous study it was shown that hydralazine and valproate had an additive effect upon the upregulation of HLA class-I antigen expression and antigen-specific CTL response in cervical cancer (37) which supports their use in combination.

Hydralazine and valproate in combination have shown to upregulate the expression of hundreds of genes in preclinical and clinical studies (6,38-39). Current data on transcriptional changes induced in cancer cell lines by epigenetic agents indicate that not all upregulated genes have $\mathrm{CpG}$ islands 
A
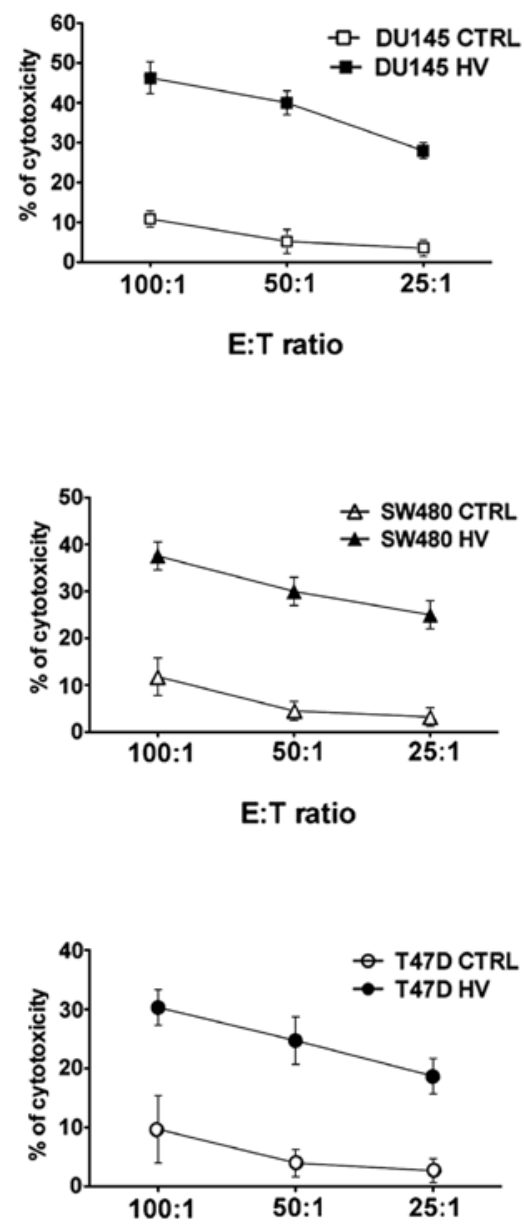

E:T ratio

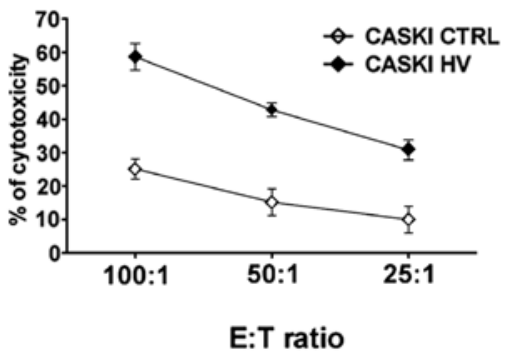

B

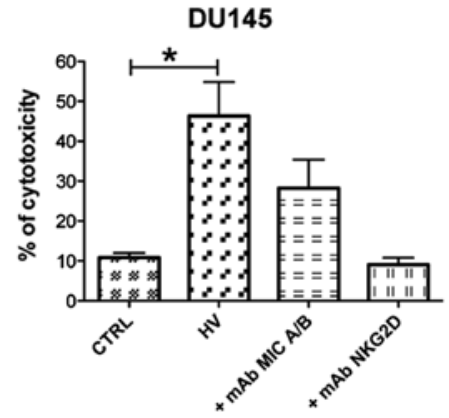

SW480

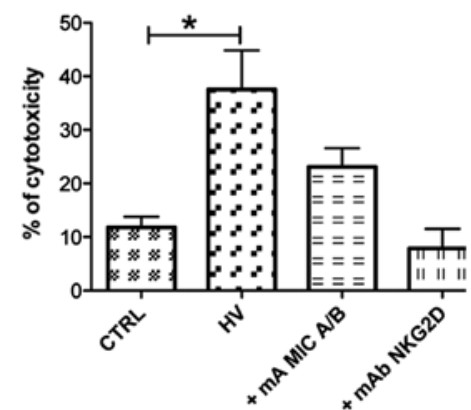

T47D

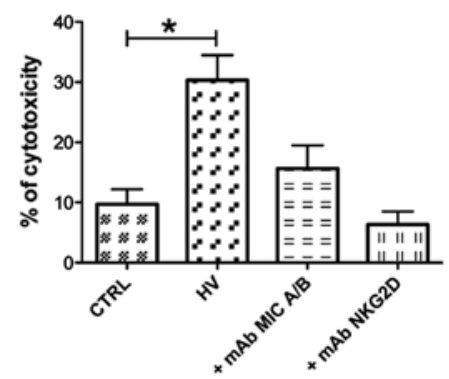

CASKI

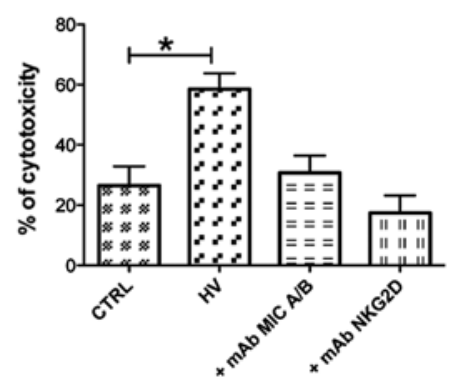

Figure 5. Enhanced natural killer (NK) cell-mediated lysis following treatment with HV. The cells were incubated for five days with HV then examined for their sensitivity to killing by cultuted NK cells from healthy individuals at different ratios (A). The 1:100 ratio is shown in bar graphs, it also examines the effect of preincubation of target cells with anti-MICA/B and incubation of NKG2D antibody with effector cells, ${ }^{*}$ p $<0.05$ (B).

in their promoters and theoretically silenced by epigenetic mechanisms, but that gene upregulation in a proportion of them is secondary to pathway activation (39). On this basis, and without detailed analysis at the promoter of NKGD2 ligand-coding genes, the results here obtained could have resulted from pathway activation induced by these drugs. Nevertheless, the Sp1 transcription factor has an important regulatory role in the expression of MICA and MICB genes (32) and it is known that $\mathrm{Spl}$ can recruit repressor complexes, such as $\operatorname{Sin} 3 \mathrm{~A}$ HDAC1/HDAC2, to repress gene transcription $(40,41)$ and that it directly interacts with DNA cytosine methyltransferase-1 (42) which suggests that Sp1 serves as a platform for recruitment of transcriptional repressors. This fact may explain that several epigenetic drugs share the ability of upregulating the expression of NKGD2 ligands by interfering with the inhibitory role of $\mathrm{Sp} 1$ in their regulation.

Regardless of the precise mechanism of action of hydralazine and valproate upon NKGD2 ligand expression and 

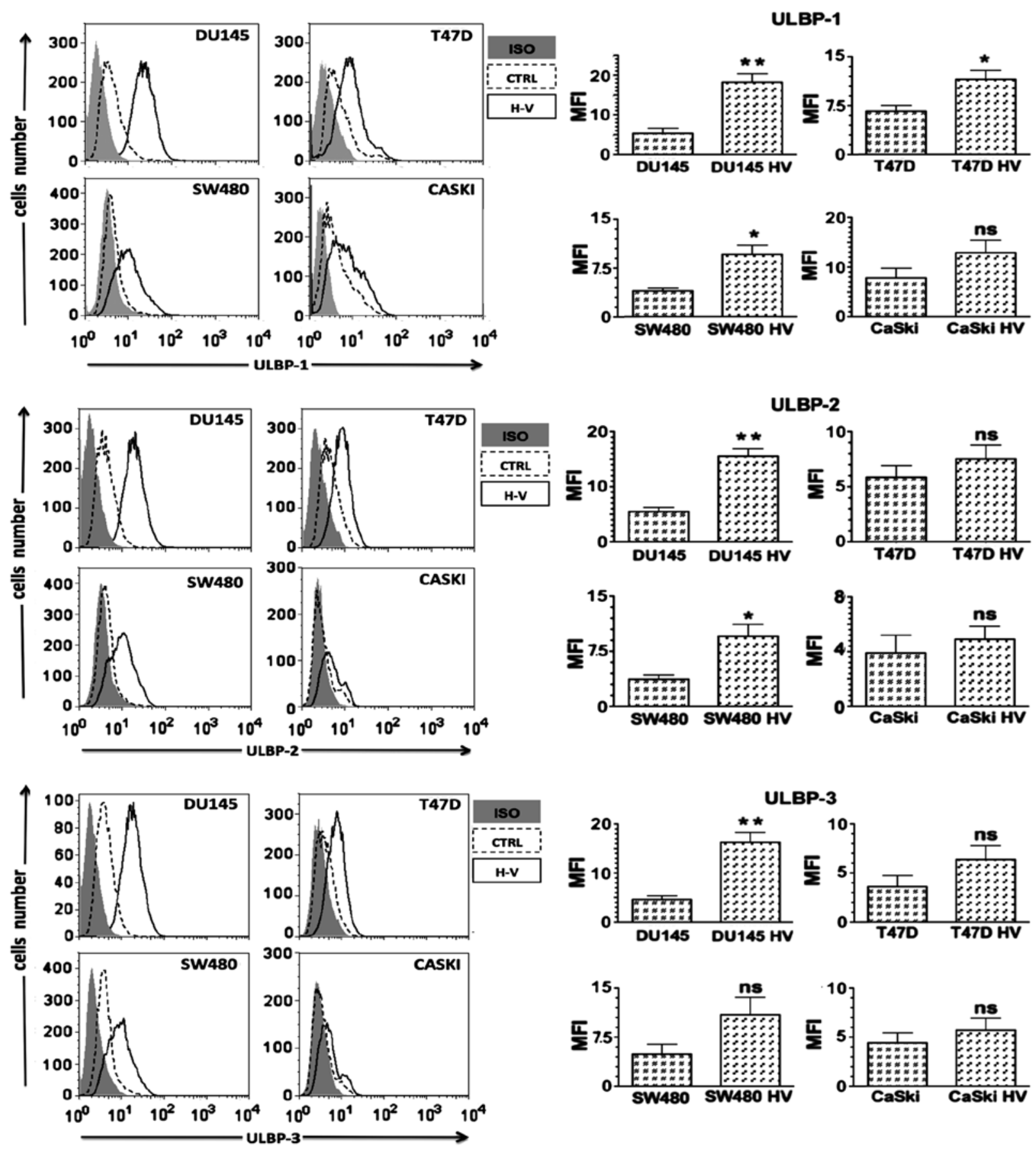

Figure 6. Treatment with HV induces the expression of UL16-binding proteins (ULBPs)1-3. The graph represents three different tests. Mean fluorescence intensity (MFI). ${ }^{*} \mathrm{p}<0.05,{ }^{* *} \mathrm{p}<0.005, \mathrm{~ns}$, non-significant.

cytotoxic activity of NK cells, the findings of this study are of clinical relevance to further assess their immunotherapeutic potential in malignancies. So far, the combination of hydralazine and valproate has shown efficacy against myelodysplastic syndrome and a number of solid tumors $(39,43-46)$ however, whether their clinical usefulness rely on their effect upon key processes of cancer such as proliferation, and apoptosis or on their effect upon the immune response to tumor remains to be demonstrated.

The major limitation of this and many studies on this issue are related to the model itself. Studies dealing with human NK cell cytotoxicity have been almost exclusively performed employing, as target cells, allogeneic tumor cell lines that express unrelated HLA class-I repertoires. Under these experimental conditions it is not possible to assess whether changes in HLA class-I expression in cancer cells may indeed affect NK cell-mediated killing (47). In addition, we have previously shown that hydralazine and valproate had an additive effect upon the upregulation of HLA class-I antigen expression and antigen-specific CTL response in cervical cancer (37). It is known that NK cells express different HLA-class I-specific inhibitory receptors $(48,49)$ which detect allelic determinants on HLA class I molecules, therefore, the overall effect of this combination on the CTL response and NK cytotoxicity needs investigation. 
In summary, our results clearly demonstrate the ability of hydralazine and valproate to increase the NK activity against epithelial cancer cell lines and suggest the potential of these drugs to reduce the plasmatic levels of soluble MICA and MICB helping in avoiding tumor-induced suppression of NK cytotoxicity against the tumor. Nevertheless, further research is needed to define the mechanism by which these drugs upregulate the NKGD2 ligands and also to investigate in autologous models whether hydralazine and valproate could increase both NK and CTL cytotoxicity.

\section{References}

1. Zhu WG and Otterson GA: The interaction of histone deacetylase inhibitors and DNA methyltransferase inhibitors in the treatment of human cancer cells. Curr Med Chem Anti-Cancer Agents 3: 187-189, 2003.

2. Hellebrekers DM, Griffioen AW and van Engeland M: Dual targeting of epigenetic therapy in cancer. Biochim Biophys Acta 1775: 76-91, 2007.

3. Catalano MG, Fortunati N, Pugliese M, Poli R, Bosco O, Mastrocola R, Aragno M and Boccurzzi G: Valproic acid, a histone deacetylase inhibitor, enhances sensitivity to doxorubicin in anaplastic thyroid cancer cells. J Endocrinol 191: 465-472, 2006.

4. Maggio SC, Rosato RR, Kramer LB, Dai Y, Rahmani M, Paik DS, Czarnik AC, Payne SG, Spiegel S and Grant S: The histone deacetylase inhibitor MS-275 interacts synergistically with fludarabine to induce apoptosis in human leukemia cells Cancer Res 64: 2590-2600, 2004.

5. Yeow WS, Ziauddin MF, Maxhimer JB, Shamimi-Noori S, Baras A, Chua A, Schrump DS and Nguyen DM: Potentiation of the anticancer effect of valproic acid, an antiepileptic agent with histone deacetylase inhibitory activity, by the kinase inhibitor Staurosporine or its clinically relevant analogue UCN-01. Br J Cancer 94: 1436-1445, 2006.

6. Chavez-Blanco A, Perez-Plasencia C, Perez-Cardenas E, Carrasco-Legleu C, Rangel-Lopez E, Segura-Pacheco B, TajaChayeb L, Trejo-Becerril C, Gonzalez-Fierro A, Candelaria M, Cabrera G and Duenas-Gonzalez A: Antineoplastic effects of the DNA methylation inhibitor hydralazine and the histone deacetylase inhibitor valproic acid in cancer cell lines. Cancer Cell Int 6: $2,2006$.

7. Tomasi TB, Magner WJ and Khan AN: Epigenetic regulation of immune escape genes in cancer. Cancer Immunol Immunother 55: 1159-1184, 2006.

8. Campoli $\mathrm{M}$ and Ferrone S: HLA antigen changes in malignant cells: epigenetic mechanisms and biologic significance. Oncogene 27: 5869-5885, 2008.

9. Karpf AR: A potential role for epigenetic modulatory drugs in the enhancement of cancer/germ-line antigen vaccine efficacy. Epigenetics 1: 116-120, 2006

10. Fernández-Morera JL, Calvanese V, Rodríguez-Rodero S, Menéndez-Torre E and Fraga MF: Epigenetic regulation of the immune system in health and disease. Tissue Antigens 76: 431-439, 2010.

11. Lodoen M, Ogasawara K, Hamerman JA, Arase H, Houchins JP, Mocarski ES and Lanier LL: NKG2D-mediated natural killer cell protection against cytomegalovirus is impaired by viral gp40 modulation of retinoic acid early inducible 1 gene molecules. J Exp Med 197: 1245-1253, 2003.

12. Welte SA, Sinzger C, Lutz SZ, Singh-Jasuja H, Sampaio KL, Eknigk U, Rammensee HG and Steinle A: Selective intracellular retention of virally induced NKG2D ligands by the human cytomegalovirus UL16 glycoprotein. Eur J Immunol 33: 194-203, 2003.

13. Moretta L and Moretta A: Unravelling natural killer cell function: triggering and inhibitory human NK receptors. EMBO J 23: 255-259, 2004

14. Bryceson YT and Ljunggren HG: Tumor cell recognition by the NK cell activating receptor NKG2D. Eur J Immunol 38: 2927-2968, 2008

15. Waldhauer I and Steinle A: NK cells and cancer immunosurveillance. Oncogene 27: 5932-5943, 2008.
16. Smyth MJ, Swann J, Cretney E, Zerafa N, Yokoyama WM and Hayakawa Y: NKG2D function protects the host from tumor initiation. J Exp Med 202: 583-588, 2005.

17. Hayakawa $Y$ and Smyth MJ: Innate immune recognition and suppression of tumors. Adv Cancer Res 95: 293-322, 2006.

18. Shankaran V, Ikeda H, Bruce AT, White JM, Swanson PE, Old LJ, Old LJ and Schreiber RD: IFNgamma and lymphocytes prevent primary tumour development and shape tumour immunogenicity. Nature 410: 1107-1111, 2001.

19. Dunn GP, Old LJ and Schreiber RD: The three Es of cancer immunoediting. Annu Rev Immunol 22: 329-360, 2004.

20. Bitzer M, Armeanu S, Prinz F, Ungerechts G, Wybranietz W, Spiegel M, Bernlöhr C, Cecconi F, Gregor M, Neubert WJ, Schulze-Osthoff K and Lauer UM: Caspase-8 and Apaf-1independent caspase-9 activation in Sendai virus-infected cells. J Biol Chem 277: 29817-19824, 2002.

21. Aktas E, Can U, Sema Bilgic K, Erten G and Deniz G: Relationship between CD107a expression and cytotoxic activity. Cell Immunol 254: 149-154, 2009

22. Smyth MJ, Swann J, Cretney E, Zerafa N, Yokoyama WM and Hayakawa Y: NKG2D function protects the host from tumor initiation. J Exp Med 202: 583-588, 2005.

23. Guerra N, Tan YX, Joncker NT, Choy A, Gallardo F, Xiong N, Knoblaugh S, Cado D, Greenberg NM and Raulet DH: NKG2Ddeficient mice are defective in tumor surveillance in models of spontaneous malignancy. Immunity 28: 571-580, 2008.

24. Gonzalez S, Groh V and Spies T: Immunobiology of human NKG2D and its ligands. Curr Top Microbiol Immunol 298: 121-138, 2006.

25. Groh V, Bahram S, Bauer S, Herman A, Beauchamp M and Spies T: Cell stress-regulated human major histocompatibility complex class I gene expressed in gastrointestinal epithelium. Proc Natl Acad Sci USA 93: 12445-12450, 1996.

26. Clayton A, Mitchell JP, Court J, Linnane S, Mason MD and Tabi Z: Human tumor-derived exosomes down-modulate NKG2D expression. J Immunol 180: 7249-7258, 2008.

27. Li K, Mandai M, Hamanishi J, Matsumura N, Suzuki A, Yagi H, Yamaguchi K, Baba T, Fujii S and Konishi I: Clinical significance of the NKG2D ligands, MICA/B and ULBP2 in ovarian cancer: high expression of ULBP2 is an indicator of poor prognosis. Cancer Immunol Immunother 58: 641-652, 2009.

28. Paschen A, Sucker A, Hill B, Moll I, Zapatka M, Nguyen XD, Sim GC, Gutmann I, Hassel J, Becker JC, Steinle A, Schadendorf D and Ugurel S: Differential clinical significance of individual NKG2D ligands in melanoma: soluble ULBP2 as an indicator of poor prognosis superior to S100B. Clin Cancer Res 15: 5208-5215, 2009.

29. Armeanu S, Bitzer M, Lauer UM, Venturelli S, Pathil A, Krusch M, Kaiser S, Jobst J, Smirnow I, Wagner A, Steinle A and Salih HR: Natural killer cell-mediated lysis of hepatoma cells via specific induction of NKG2D ligands by the histone deacetylase inhibitor sodium valproate. Cancer Res 65: 6321-6329, 2005.

30. Diermayr S, Himmelreich H, Durovic B, Mathys-Schneeberger A, Siegler U, Langenkamp U, Hofsteenge J, Gratwohl A, Tichelli A, Paluszewska M, Wiktor-Jedrzejczak W, Kalberer CP and WodnarFilipowicz A: NKG2D ligand expression in AML increases in response to HDAC inhibitor valproic acid and contributes to allorecognition by NK-cell lines with single KIR-HLA class I specificities. Blood 111: 1428-1436, 2008.

31. Poggi A, Catellani S, Garuti A, Pierri I, Gobbi M and Zocchi MR: Effective in vivo induction of NKG2D ligands in acute myeloid leukaemias by all-trans-retinoic acid or sodium valproate. Leukemia 23: 641-648, 2009.

32. Zhang C, Wang Y, Zhou Z, Zhang J and Tian Z: Sodium butyrate upregulates expression of NKG2D ligand MICA/B in HeLa and HepG2 cell lines and increases their susceptibility to NK lysis. Cancer Immunol Immunother 58: 1275-1285, 2009.

33. Kato N, Tanaka J, Sugita J, Toubai T, Miura Y, Ibata M, Syono Y, Ota S, Kondo T, Asaka M and Imamura M: Regulation of the expression of MHC class I-related chain A, B (MICA, MICB) via chromatin remodeling and its impact on the susceptibility of leukemic cells to the cytotoxicity of NKG2D-expressing cells. Leukemia 21: 2103-2108, 2007.

34. Tang KF, He CX, Zeng GL, Wu J, Song GB, Shi YS, Zhang WG, Huang AL, Steinle A and Ren H: Induction of MHC class I-related chain B (MICB) by 5-aza-2'-deoxycytidine. Biochem Biophys Res Commun 370: 578-583, 2008.

35. Kim JY, Bae JH, Lee SH, Lee EY, Chung BS, Kim SH and Kang CD: Induction of NKG2D ligands and subsequent enhancement of NK cell-mediated lysis of cancer cells by arsenic trioxide. J Immunother 31: 475-486, 2008. 
36. Fu HY, Shen JZ, Wu Y, Shen SF, Zhou HR and Fan LP: Arsenic trioxide inhibits DNA methyltransferase and restores expression of methylation-silenced CDKN2B/CDKN2A genes in human hematologic malignant cells. Oncol Rep 24: 335-343, 2010.

37. Mora-García Mde L, Duenas-González A, Hernández-Montes J, De la Cruz-Hernández E, Pérez-Cárdenas E, Weiss-Steider B, Santiago-Osorio E, Ortíz-Navarrete VF, Rosales VH, Cantú D, Lizano-Soberón M, Rojo-Aguilar MP and MonroyGarcía A: Up-regulation of HLA class-I antigen expression and antigen-specific CTL response in cervical cancer cells by the demethylating agent hydralazine and the histone deacetylase inhibitor valproic acid. J Transl Med 4: 55, 2006.

38. Arce C, Pérez-Plasencia C, González-Fierro A, de la CruzHernández E, Revilla-Vázquez A, Chávez-Blanco $\mathrm{A}$, Trejo-Becerril C, Pérez-Cárdenas E, Taja-Chayeb L, Bargallo E, Villarreal P, Ramírez T, Vela T, Candelaria M, Camargo MF, Robles E and Dueñas-González A: A proof-of-principle study of epigenetic therapy added to neoadjuvant doxorubicin cyclophosphamide for locally advanced breast cancer. PLoS One 1: E98, 2006.

39. De la Cruz-Hernández E, Perez-Plasencia C, Pérez-Cardenas E, Gonzalez-Fierro A, Trejo-Becerril C, Chávez-Blanco A, TajaChayeb L, Vidal S, Gutiérrez O, Dominguez GI, Trujillo JE and Duenas-González A: Transcriptional changes induced by epigenetic therapy with hydralazine and magnesium valproate in cervical carcinoma. Oncol Rep 25: 399-407, 2011.

40. Zhang Y and Dufau ML: Repression of the luteinizing hormone receptor gene promoter by cross talk among EAR3/COUP-TFI, Sp1/Sp3, and TFIIB. Mol Cell Biol 23: 6958-6972, 2003.

41. Clem BF and Clark BJ: Association of the mSin3A-histone deacetylase $1 / 2$ corepressor complex with the mouse steroidogenic acute regulatory protein gene. Mol Endocrinol 20: 100-113, 2006.

42. Estève PO, Chin HG and Pradhan S: Molecular mechanisms of transactivation and doxorubicin-mediated repression of survivin gene in cancer cells. J Biol Chem 282: 2615-2625, 2007.
43. Candelaria M, Herrera A, Labardini J, González-Fierro A, Trejo-Becerril C, Taja-Chayeb L, Pérez-Cárdenas E, de la Cruz-Hernández E, Arias-Bofill D, Vidal S, Cervera E and DueñasGonzalez A: Hydralazine and magnesium valproate as epigenetic treatment for myelodysplastic syndrome. Preliminary results of a phase-II trial. Ann Hematol 90: 379-387, 2001.

44. Candelaria M, Gallardo-Rincón D, Arce C, Cetina L, AguilarPonce JL, Arrieta O, González-Fierro A, Chávez-Blanco A, de la Cruz-Hernández E, Camargo MF, Trejo-Becerril C, PérezCárdenas E,Pérez-Plasencia C,Taja-ChayebL, Wegman-Ostrosky T, Revilla-Vazquez A and Dueñas-González A: A phase II study of epigenetic therapy with hydralazine and magnesium valproate to overcome chemotherapy resistance in refractory solid tumors. Ann Oncol 18: 1529-1538, 2007.

45. Coronel J, Cetina L, Pacheco I, Trejo-Becerril C, GonzálezFierro A, de la Cruz-Hernandez E, Perez-Cardenas E, Taja-Chayeb L, Arias-Bofill D, Candelaria M, Vidal S and DueñasGonzález A: A double-blind, placebo-controlled, randomized phase III trial of chemotherapy plus epigenetic therapy with hydralazine valproate for advanced cervical cancer. Preliminary results. Med Oncol Oct 8, 2010. [Epub ahead of print].

46. Candelaria M,CetinaL,Pérez-Cárdenas E, de la Cruz-Hernández E, González-Fierro A, Trejo-Becerril C, Taja-Chayeb L, Chanona J, Arias D and Dueñas-González A: Epigenetic therapy and cisplatin chemoradiation in FIGO stage IIIB cervical cancer. Eur J Gynaecol Oncol 3: 386-391, 2010.

47. Carrega P, Pezzino G, Queirolo P, Bonaccorsi I, Falco M, Vita G, Pende D, Misefari A, Moretta A, Mingari MC, Moretta L and Ferlazzo G: Susceptibility of human melanoma cells to autologous natural killer (NK) cell killing: HLA-related effector mechanisms and role of unlicensed NK cells. PLoS One 4: E8132, 2009.

48. Moretta A, Bottino C, Vitale M, Pende D, Biassoni R, Pende D, Biassoni R, Mingari MC and Moretta L: Receptors for HLA class-I molecules in human natural killer cells. Annu Rev Immunol 14: 619-648, 1996.

49. Long EO: Regulation of immune responses through inhibitory receptors. Annu Rev Immunol 17: 875-904, 1999. 